Supporting Information

\title{
Effect of Rhodium Modification on Activity of Platinum Nanoparticle-loaded Carbon Catalysts for Electrochemical Toluene Hydrogenation
}

Toyoki Imada, Masanobu Chiku, Eiji Higuchi, Hiroshi Inoue*

Department of Applied Chemistry, Graduate School of Engineering, Osaka Prefecture

University, Sakai, Osaka 599-8531, Japan 


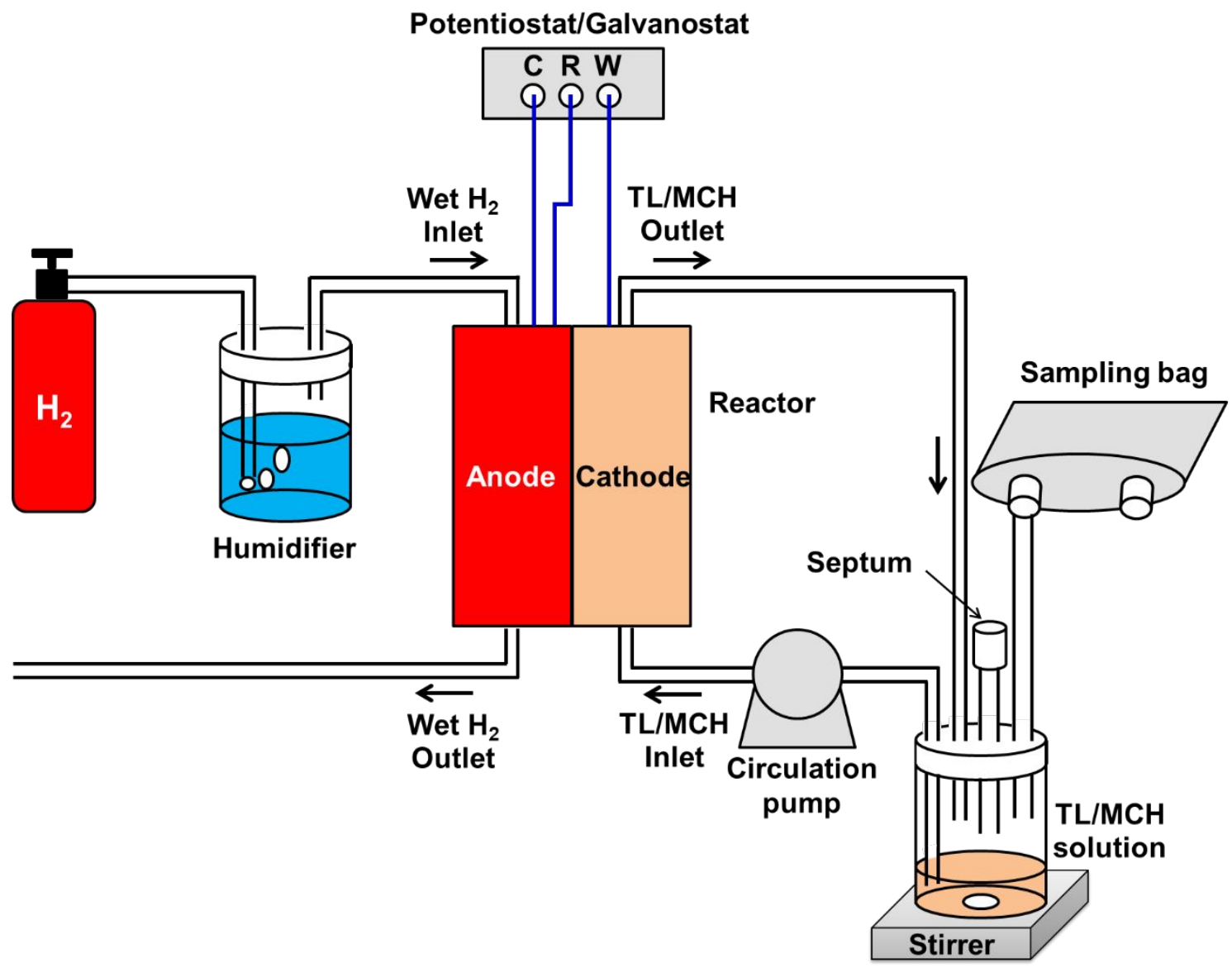

Figure S1. A schematic diagram of electrochemical hydrogen pump TL hydrogenation system. 


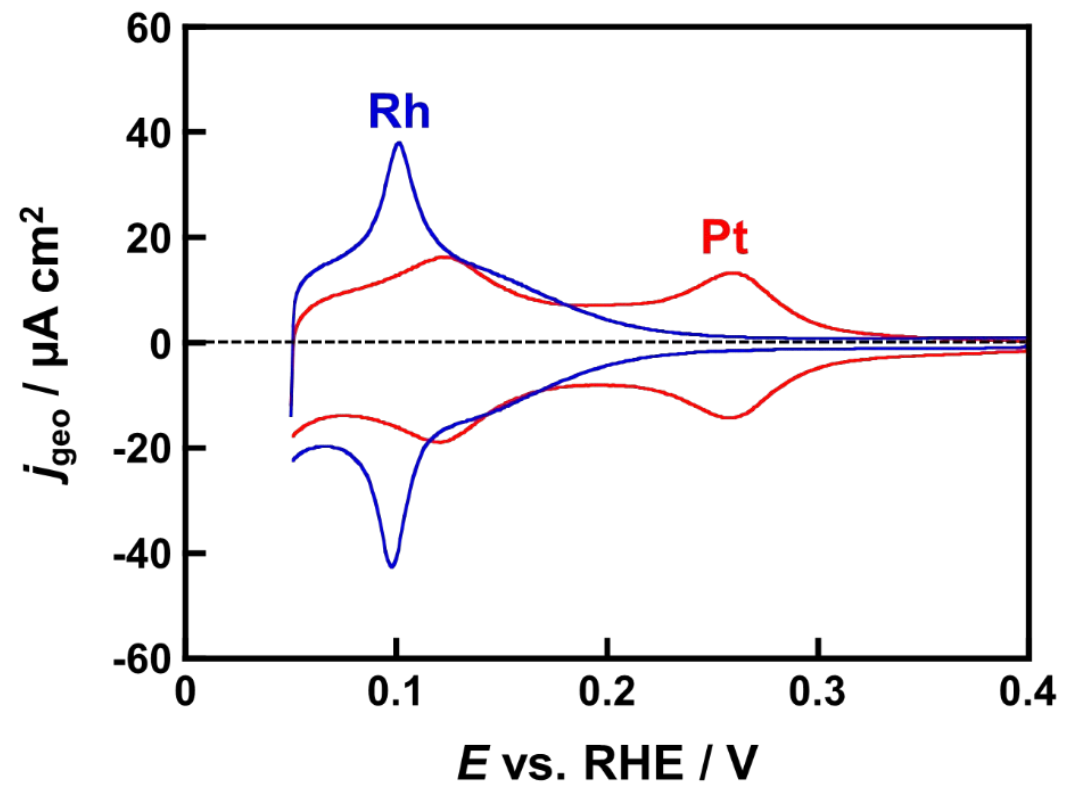

Figure S2. Cyclic voltammograms of polycrystalline $\mathrm{Pt}$ (red) and $\mathrm{Rh}$ (blue) electrodes each in an Ar-saturated solution of $0.5 \mathrm{M} \mathrm{H}_{2} \mathrm{SO}_{4}$ at $5{ }^{\circ} \mathrm{C}$. Sweep rate: $10 \mathrm{mV} \mathrm{s}^{-1}$. 
Table S1. Various parameters for $\mathrm{Rh}_{\mathrm{x}} / \mathrm{Pt} / \mathrm{C}$ electrodes.

$\begin{array}{ccccc}\text { Electrode } & \begin{array}{c}Q_{\mathrm{H}-\text { des,Rh/Pt/C }} \\ \mathrm{mC}\end{array} & \begin{array}{c}Q_{\mathrm{H}-\mathrm{des}, \mathrm{Rh}} \\ \mathrm{mC}\end{array} & \begin{array}{c}E C S A_{\mathrm{Rh}} \\ \mathrm{cm}^{2}\end{array} & \begin{array}{c}E C S A_{\mathrm{Pt}} \\ \mathrm{cm}^{2}\end{array} \\ \mathrm{Rh}_{0.19} / \mathrm{Pt} / \mathrm{C} & 198 & 36.6 & 166 & 769 \\ \mathrm{Rh}_{0.38} / \mathrm{Pt} / \mathrm{C} & 150 & 38.1 & 172 & 533 \\ \mathrm{Rh}_{0.56} / \mathrm{Pt} / \mathrm{C} & 180 & 58.9 & 267 & 577 \\ \mathrm{Rh}_{0.76} / \mathrm{Pt} / \mathrm{C} & 167 & 65.6 & 297 & 483 \\ \mathrm{Pt} / \mathrm{C} & 221 & - & - & 1052\end{array}$

